\title{
Original
}

\section{Effect of presurgical long-acting octreotide treatment in acromegaly patients with invasive pituitary macroadenomas: a prospective randomized study}

\author{
Ming Shen ${ }^{1}{ }_{*}$, Xuefei Shou ${ }^{1}{ }_{*}$, Yongfei Wang ${ }^{1)}$, Zhaoyun Zhang ${ }^{2)}$, Jinsong $\mathrm{Wu}^{1)}$, Ying Mao ${ }^{1)}$, Shiqi $\mathrm{Li}^{1)}$ \\ and Yao Zhao ${ }^{1)}$ \\ 1) Department of Neurosurgery, Huashan Hospital, Shanghai Medical College, Fudan University, Shanghai 200040, China \\ 2) Department of Endocrinology, Huashan Hospital, Shanghai Medical College, Fudan University, Shanghai 200040, China
}

\begin{abstract}
Therapeutic effects of presurgical long-acting octreotide treatment on tumor shrinkage, and short- and long-term postoperative GH and IGF-1 levels of acromegaly patients with invasive pituitary macroadenomas were investigated prospectively in Huashan Hospital, Shanghai, China. Thirty-nine untreated acromegaly patients, all with invasive pituitary macroadenomas, were randomly divided into two groups: experimental group $(n=19)$, and control group ( $n=20)$. Patients in the experimental group received a three-month course of long-acting octreotide treatment before transsphenoidal surgery; the control group underwent surgery directly. Tumor shrinkage after drug treatment and short- and long-term postoperative GH and IGF-1 levels were analyzed in the two groups. Long-acting octreotide treatment reduced tumor size from $7893 \pm$ 6450 to $4794 \pm 4682 \mathrm{~mm}^{3}$. Mean shrinkage rate was $37.4 \pm 30.9 \%$. GH and IGF-1 levels of the experimental group were lower than the control group at 3 months, 6 months after surgery, and after long-term follow-up. Remission rate (both GH and IGF-1 normal) of the experimental group was higher at 3 and 6 months follow-up, but exhibited no advantage in longterm follow-up. In the experimental group, the total resection rate was higher in patients whose Hardy-Knosp grading decreased to $\leq 2$ than those whose Hardy-Knosp grading is still $\geq 3$ after drug pretreatment. In conclusion, presurgical long-acting octreotide treatment effectively reduces tumor size and invasion, which helps enhance early remission rates of invasive macroadenomas by transsphenoidal surgery, but does not appear to improve the long-term cure rate.
\end{abstract}

Key words: Acromegaly, Pituitary macroadenomas, Presurgical long-acting octreotide treatment

THE RECENT paradigm for managing acromegaly includes microsurgery or endoscopic surgery (transsphenoidal surgery or craniotomy), pharmacological therapy (somatostatin analogue, growth hormonereceptor antagonist, dopamine receptor agonists) and radiosurgery which reverse excessive growth hormone (GH) secretion, and shrink or ablate tumors without compromising normal pituitary function. Maximal control of GH level, reduction of systemic complications and mortality, control of tumor growth, preservation of pituitary function, and extension of life expectancy are the aims of disease management. But these

Received Jul. 2, 2010; Accepted Sep. 27, 2010 as K10E-203

Released online in J-STAGE as advance publication Nov.16, 2010

Correspondence to: Shiqi Li and Yao Zhao, Department of Neurosurgery, Huashan Hospital, Shanghai Medical College, Fudan University, 12\#, Wulumuqi Zhong Road, Shanghai, 200040, P. R. China. E-mail: zhaoyaohs@hotmail.com

* These authors contributed equally to this work. aims are difficult to achieve in most patients with macroadenomas, especially invasive tumors. The main reason is it is difficult to totally resect large invasive tumors, hence optimal and long-term biochemical control is seldom achieved.

Transsphenoidal surgery has been accepted as firstline therapy for GH-secreting pituitary adenoma [1]. Surgical results depend on tumor size, tumor invasion, and preoperative GH levels [2-5].

The somatostatin analogue, octreotide and its longacting preparation has been used to treat acromegaly for the past two decades. A review of the literature shows that long-acting octreotide reduces GH level, tumor size, and relieves systemic symptoms [6-9]. Nevertheless long-term use of somatostatin analogs may be limited due to the cost [10], thus short-term presurgical use of long-acting octreotide may be costeffective. Whether or not presurgical medical treatment improves the remission rates of invasive mac- 
Table 1 Outcomes of presurgical long-acting octreotide treatment in acromegaly patients

\begin{tabular}{lcccccc}
\hline Author & Year & Study types & $\begin{array}{c}\text { No. of } \\
\text { patients }\end{array}$ & Tumor characteristic & $\begin{array}{c}\text { Surgical } \\
\text { remission (\%) }\end{array}$ & Conclusion \\
\hline Barkan & 1988 & Retrospective & 10 & 10 macro, 10 in & 80 & Validity \\
Morante & 1994 & Retrospective & 10 & 10 macro, 10 in & 60 & Validity \\
$\begin{array}{l}\text { Plockinger } \\
\text { treated/ not treated }\end{array}$ & 2005 & Prospective, control & 48 & 48 macro & $75 / 75$ & Invalidity \\
$\begin{array}{l}\text { Colao } \\
\begin{array}{l}\text { Carlsen } \\
\text { treated/not treated }\end{array}\end{array}$ & 2006 & Retrospective & 86 & 5 micro, 63 macro, 18 in & 58 & Validity \\
\hline
\end{tabular}

Table 2 Clinical material of patients

\begin{tabular}{lccc}
\hline & Experimental group $(\mathrm{n}=19)$ & Control group $(\mathrm{n}=20)$ & $P$ value \\
\hline Age (years) & $39.2 \pm 10.8$ & $44.1 \pm 10.5$ & 0.16 \\
Follow-up (months) & $28.8 \pm 13.4$ & $26.6 \pm 4.2$ & 0.59 \\
Sex (M/F) & $11 / 8$ & $7 / 13$ & 0.21 \\
Latent period (years) & $6.5 \pm 4.6$ & $6.4 \pm 3.9$ & 0.93 \\
Tumor volume (mm $\left.{ }^{3}\right)$ & $7893 \pm 6450$ & $7616 \pm 6163$ & 0.79 \\
\hline
\end{tabular}

roadenomas and boosts the final cure rate is unclear [11-15]. In assessing the historical experience, analysis is challenging because most studies are retrospective. The lack of direct comparisons, reliance on single $\mathrm{GH}$ values, a large range of octreotide doses utilized, and relatively small numbers of patients, are among the confounding factors $[10,13,16]$. Besides, the different proportion of patients with different tumor characters (size and invasiveness) makes these conclusions less instructive (Table 1).

Therefore, we designed this prospective comparative study. Thirty-nine acomegaly patients, all with invasive macroadenomas, from January 2005 to June 2006 in our center, were randomly divided into an experimental group $(n=19)$ and a control group $(n=20)$. Patients in the experimental group received a 3-monthcourse of long-acting octreotide (drug pretreatment, 20 mg i.m. every 28 days, for 3 months) before transsphenoidal surgery; the other group underwent surgery directly. Imaging and endocrine results were analyzed for the two groups, so as to evaluate therapeutic effects of long-acting octreotide pretreatment on tumor size reduction, short- and long-term postoperative GH and type-1 insulin like growth factor (IGF-1) levels in patients with GH-secreting invasive pituitary macroadenomas. This was an open, prospective, comparative, randomized clinical study. Written informed con- sent was obtained from each patient before inclusion and the Declaration of Helsinki was followed throughout the study. The study was approved by the hospital Ethics Committee before commencing.

\section{Materials and Methods}

\section{Patients (Table 2)}

All patients were adults over 18 years old, and the diagnosis was based on clinical features of acromegaly (typically, carpal tunnel syndrome, acroparesthesia, hyperhidrosis, arthralgias, debility, sleep apnea, visual field defects, soft tissue swelling, lumbodorsal pain, and headache) [17]. Nadir GH levels after oral glucose tolerance test (OGTT) were $>1 \mu \mathrm{g} / \mathrm{L}$, and IGF-1 levels were elevated for age and gender adjusted ranges, and pituitary magnetic resonance imaging (MRI) showed pituitary tumors $>10 \mathrm{~mm}$ in diameter, which invaded at least one direction to suprasellar, parasellar or inferosellar regions, and according to Hardy-Knosp grade \& stage standard [18], the tumors were $\geq \mathrm{III}$ in grade or C to $\mathrm{E}$ in stage. We assigned it $\geq 3$ in this situation, and $\leq 2$ when the tumors were $\leq I I$ in grade and 0 to $\mathrm{B}$ in stage. All patients planned to undergo transsphenoidal surgery, and had no history of prior surgery, radiotherapy or medical treatment. They were randomly divided into two groups. The experimental group comprised 
19 patients with pituitary macroadenoma ( 8 women, 11 men; mean age $39.2 \pm 10.8$ years) Acromegaly developed over a period of $6.5 \pm 4.6$ years prior to diagnosis. Follow-up was $28.8 \pm 13.4$ months after surgery. The control group comprised 20 patients with acromegaly (13 women, 7 men; mean age $44.1 \pm 10.5$ years). Acromegaly developed over a period of $6.4 \pm 3.9$ years prior to diagnosis. Follow-up was $26.6 \pm 4.2$ months after surgery. All operations were performed by a single experienced surgeon in our center.

\section{Endocrine evaluation}

All patients underwent endocrine examinations before and after surgery, and additional exams before and after drug pretreatment were added to the experimental group. Endocrine testing included nadir $\mathrm{GH}$ after OGTT (the lowest GH levels measure at 0, 30, $60,90,120$ and $180 \mathrm{~min}$ after $75 \mathrm{~g}$ oral glucose) and measuring serum IGF-1 levels. GH level measurement was performed using time-resolved fluoroimmunoassay (PerkinElmer Life and Analytical Sciences, Turku, Finland); IGF-1 was measured by DSL-10-2800 ACTIVE Non-Extraction IGF-1 ELISA (Diagnostic Systems Laboratories, Inc., Webster, TX). The normal IGF-1 concentration adjusted by age and gender in Chinese population was as follows (ng/mL): 21 30 $\mathrm{y}$, male 116 329, female 117 358; 31 40 y, male 109 284, female 115 307; 41 50 y, male 94 252, female 101 267; 51 60 y, male 87 225, female 81 238; 61 70 y, male 75 212, female 69 200; 71 80 $\mathrm{y}$, male 64 188, female 59 177; $81 \mathrm{y}^{+}$, male 60 171, female 50 160. The endocrine remission criteria for acromegaly were nadir GH after OGTT less than $1 \mu \mathrm{g} / \mathrm{L}$ and IGF-1 levels within the normal ranges as matched by age and gender [19-21].

\section{Tumor size evaluation}

All patients underwent pituitary MRI examinations with spin-echo sequence T1-weighted MRI, with a 3.0-T whole-body MRI scanner (General Electric Medical Systems, Milwaukee, MI) before and after i.v. gadolinium administration. Because tumors were irregular in shape, we transferred the adopted DICOM data sets into the Dextroscope workstation (Dextroscope, Volume Interactions Pte. Ltd., Singapore) to generate a 3-D model, to calculate the precise tumor size.

\section{Drug pretreatment}

All patients underwent the tolerance and sensitivity tests to the drug. Short-acting octreotide (Sandostatin, Novartis Pharma AG, Basel, Switzerland) $0.1 \mathrm{mg}$ hypodermic injection, 3 times (8 a.m., 4 p.m., and 12 p.m.), evaluate GH level before the first injection and at 8 A.M. the next day, if the second GH level declined more than $20 \%$, the patient was considered to be sensitive to the drug [22]. Patients were randomly divided into the two groups as mentioned above.

The experimental group received a 3-month-course of long-acting octreotide (Novartis Pharma AG, Basel, Switzerland) pretreatment (20 mg i.m. every 28 days, for 3 months) before transsphenoidal surgery. Abdominal ultrasound was performed to screen for cholecystolithiasis during medication. Nadir GH levels after OGTT, IGF-1 levels and pituitary MRI were performed before and after drug pretreatment to evaluate the effects of medication. At surgery, the tumor texture was classified as soft, soft-firm, firm, firm-hard, or hard; the degree of tumor invasion to surrounding structures was classified as none, local, or extensive.

\section{Remission criteria and follow-up}

After surgery, we routinely transferred the patients to the Endocrine Department of our hospital for further medical treatment. Endocrine remission criteria for acromegaly included nadir GH after OGTT $<1 \mu \mathrm{g} / \mathrm{L}$ and IGF- 1 within the normal range matched by age and gender [19, 20, 23]. All patients underwent nadir GH and IGF-1 level evaluation, and pituitary MRI examination at 3 months, 6 months, 1 year, and annual follow-up. None of the patients withdrew from the study or was lost to follow-up during the study period. Four patients in experimental group and 7 in control group were required to receive a gamma-knife radiotherapy about 6 months after unsuccessful surgery.

\section{Statistics}

When data distribution was normal, mean \pm SE was used, otherwise median values should be calculated as M (P25 P75), but we still used mean \pm SE, to make a more uniform comparison and an easier understanding. Normal distribution was tested by the Shapiro-Wilk W test. Between-group comparisons were analyzed by $t$-test when data distribution was continuous and normal or by Wilcoxon rank-sum (Mann-Whitney) test when data distribution was continuous but abnormal. Incontinuous data were analyzed by Pearson Chi-square test when $n \geq 40$ or by Fisher's exact method when $n<40$. Ordered categories were analyzed by Cochran- 
Table 3 Nadir GH after OGTT and IGF-I levels at diagnosis (Diag), after drug treatment (PD), 3 and 6 months after surgery (PO3, and PO6) and at the last investigation (LI) of the experimental and control group.

\begin{tabular}{|c|c|c|c|c|c|c|c|c|c|c|}
\hline & \multicolumn{5}{|c|}{ Experimental group $(n=19)$} & \multicolumn{4}{|c|}{ Control group $(\mathrm{n}=20)$} & \multirow{2}{*}{$P$ value ${ }^{*}$} \\
\hline & Diag & $\mathrm{PD}$ & PO3 & PO6 & LI & Diag & PO3 & PO6 & LI & \\
\hline Nadir GH after OGTT $(\mu \mathrm{g} / \mathrm{L})$ & 34.0 & 18.1 & 3.5 & 3.8 & 3.4 & 37.8 & 7.4 & 7.8 & 7.0 & $0.56,0.0029,0.011,0.038$ \\
\hline$\%$ of patients $<1.0 \mu \mathrm{g} / \mathrm{L}$ & - & - & $42.1 \%$ & $42.1 \%$ & $36.8 \%$ & - & $10 \%$ & $15 \%$ & $15 \%$ & $-, 0.031,0.082,0.27$ \\
\hline $\mathrm{IGF}-1(\mu \mathrm{g} / \mathrm{L})$ & 914 & 884 & 340 & 324 & 327 & 889 & 505 & 474 & 431 & $0.62,0.0085,0.019,0.048$ \\
\hline$\%$ of patients normal & - & - & $42.1 \%$ & $47.4 \%$ & $36.8 \%$ & - & $10 \%$ & $20 \%$ & $20 \%$ & $-, 0.031,0.096,0.30$ \\
\hline $\begin{array}{l}\% \text { of patients nadir } \mathrm{GH}<1.0 \mu \mathrm{g} / \mathrm{L} \\
\text { plus IGF-1 normal }\end{array}$ & - & - & $31.6 \%$ & $42.1 \%$ & $31.6 \%$ & - & $5 \%$ & $10 \%$ & $10 \%$ & $-, 0.044,0.031,0.13$ \\
\hline
\end{tabular}

*Significance of difference between groups [Diag / Diag, PO3 / PO3, PO6 / PO6, LI / LI, Wilcoxon rank-sum (Mann-Whitney) test].

Mantel-Haenszel Chi-square test. Statistical evaluation was performed with Statistical software (Stata/SE 7.0). A $P$ value $<0.05$ was considered significant.

\section{Results}

\section{Comparison of nadir GH level after OGTT, IGF-1} level, and remission rates (Table 3 )

a. Data at diagnosis: Nadir GH level and IGF-1 level at diagnosis was $34.0 \pm 30.5 \mu \mathrm{g} / \mathrm{L}$, and $914 \pm 152 \mu \mathrm{g} / \mathrm{L}$ respectively in the experimental group, and $37.8 \pm 31.8$ $\mu \mathrm{g} / \mathrm{L}$ and $889 \pm 177 \mu \mathrm{g} / \mathrm{L}$ in the control group. All patients' nadir GH after OGTT was above $1 \mu \mathrm{g} / \mathrm{L}$, and IGF-1 was above the upper limit of the age and gender-matched range. Nadir GH and IGF-1 levels did not achieve statistical significance between groups $\left(P_{G H}=0.56, P_{I G F-1}=0.62\right)$.

b. GH levels: In the experimental group, nadir GH levels were $18.1 \pm 20.5,3.5 \pm 5.0,3.8 \pm 5.3$, and $3.4 \pm 3.8$ $\mu \mathrm{g} / \mathrm{L}$, respectively after drug-pretreatment, 3 months, 6 months after surgery and long-term follow-up. Percentage of patients achieving nadir GH $<1 \mu \mathrm{g} / \mathrm{L}$ was $42.1 \%$ (8/19), 42.1\% (8/19) and 36.8\% (7/19), respectively, at 3 months, 6 months after surgery and long-term follow-up. In the control group, nadir GH levels were 7.4 $\pm 7.0,7.8 \pm 7.4$, and 7.0 $\pm 7.1 \mu \mathrm{g} / \mathrm{L}$, respectively, at 3 months, 6 months and long-term follow-up. Percentage of patients with nadir $\mathrm{GH}<1 \mu \mathrm{g} / \mathrm{L}$ was $10 \%$ (2/20), $15 \%(3 / 20)$, and $15 \%(3 / 20)$, respectively, at 3 months, 6 months after surgery and long-term follow-up. Nadir GH levels at 3 months, 6 months and long-term follow-up reached statistical significance $(P=0.0029,0.011,0.038)$. Percentage of patients with nadir $\mathrm{GH}<1 \mu \mathrm{g} / \mathrm{L}$ reached statistical significance at 3 months follow-up ( $P=0.031)$, while results did not reach statistical significance at 6 months after surgery and during long-term follow-up ( $P=0.082$ and 0.27 ). c. IGF-1 levels: In the experimental group, IGF-1 levels were $884 \pm 212,340 \pm 179,324 \pm 188$, and $327 \pm 145 \mu \mathrm{g} / \mathrm{L}$, after drug-pretreatment, and at 3 months, 6 months after surgery and long-term follow-up, respectively. Percentage of patients with normal IGF-1 matched by age and gender was $42.1 \%(8 / 19), 47.4 \%$ (9/19), and $36.8 \%$ (7/19), at 3 months, 6 months after surgery and long-term follow-up respectively. In the control group, IGF-1 levels were $505 \pm 190,474 \pm 194,431 \pm 166 \mu \mathrm{g} / \mathrm{L}$, at 3 months, 6 months after surgery, and long-term follow-up, respectively. Percentage of patients with normal IGF-1 matched by age and gender was $10 \%(2 / 20)$, $20 \%(4 / 20)$ and $20 \%(4 / 20)$, at 3 months, 6 months after surgery, and long-term follow-up respectively. IGF-1 levels at 3 months, 6 months after surgery, and long-term follow-up reached statistical significance ( $P=0.0085$, $0.019,0.048)$. Percentage of patients with normal IGF-1 matched by age and gender reached statistical significance at 3 months follow-up ( $P=0.031)$, while the data did not achieve statistical significance at 6 months and at long-term follow-up ( $P=0.096$ and 0.30 ).

d. Remission rates: Remission rate (nadir $\mathrm{GH}<1 \mu \mathrm{g} / \mathrm{L}$ and normal IGF-1 level) of the experimental group was higher than the control group at 3 and 6 months follow-up [31.6\% (6/19) vs 5\% (1/20), 42.1\% (8/19) vs $10 \%(2 / 20), P=0.044$ and 0.031 , but showed no advantage at long-term follow-up [31.6\% (6/19) vs $10 \%(2 / 20), P=0.13]$.

\section{Symptomatic relief of the experimental group after drug pretreatment (Fig. 1 and Table 4)}

Typical symptoms of acromegaly including carpal tunnel syndrome, acroparesthesia, hyperidrosis, 

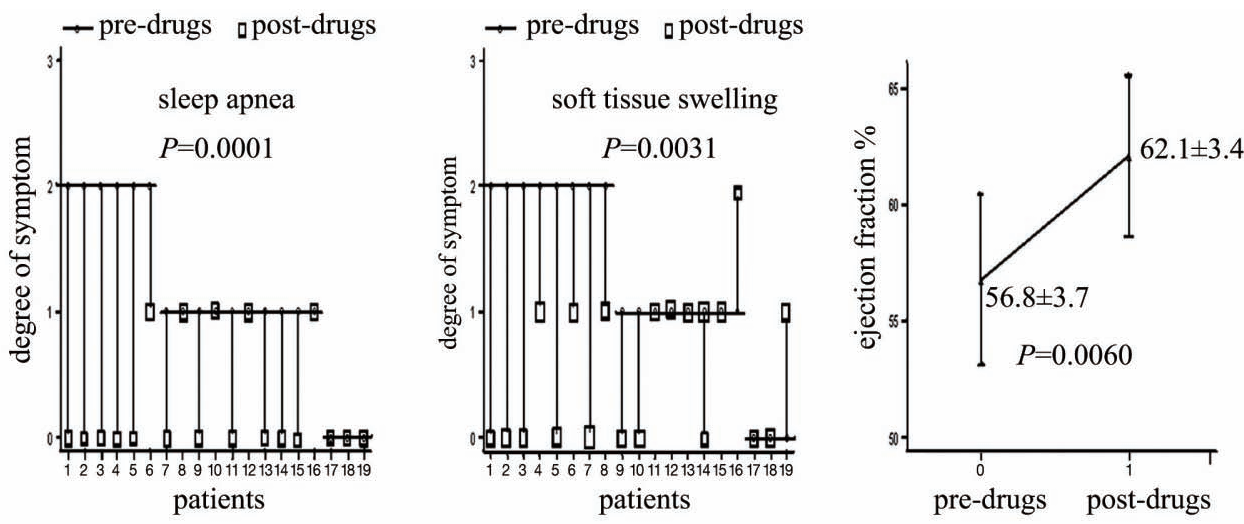

Fig. 1 Presurgical octreotide treatment improved patients' symptoms such as sleep apnea and soft tissue swelling, and improved patients' cardiac function such as Left Ventricular Ejection Fraction (LVEF) $[P=0.0060$, Wilcoxon rank-sum (Mann-Whitney) test]. The degree of symptom was graded as none, slight, midrange, or severe, and was assigned as 0,1 , 2, or 3 respectively.

Table 4 Median fasting and 2-h glucose concentration, mean artery pressure, and percentage of patients with impaired glucose tolerance (IGT) or diabetes mellitus (DM) or high blood pressure (HBP) at diagnosis (Diag), after drug treatment (PD), 3 and 6 months after surgery (PO3, and PO6) and at the last investigation (LI) of the experimental and control group

\begin{tabular}{|c|c|c|c|c|c|c|c|c|c|c|}
\hline & \multicolumn{5}{|c|}{ Experimental group $(n=19)$} & \multicolumn{4}{|c|}{ Control group $(\mathrm{n}=20)$} & \multirow{2}{*}{$P$ value ${ }^{*}$} \\
\hline & Diag & PD & $\mathrm{PO} 3$ & PO6 & LI & Diag & PO3 & PO6 & LI & \\
\hline \multicolumn{11}{|l|}{ Glucose (mmol/L) } \\
\hline Fasting & 6.9 & $6.3^{\dagger}$ & $5.8^{\dagger}$ & $5.4^{\dagger}$ & $5.6^{\dagger}$ & 7.0 & $5.9^{\dagger}$ & $5.7^{\dagger}$ & $5.7^{\dagger}$ & $0.80,0.57,0.49,0.17$ \\
\hline 2-h & 12.7 & $11.6^{\dagger}$ & $11.2^{\dagger}$ & $11^{\dagger}$ & $11.1^{\dagger}$ & 13 & $11.3^{\dagger}$ & $10.9^{\dagger}$ & $11^{\dagger}$ & $0.61,0.55,0.68,0.23$ \\
\hline $\begin{array}{l}\text { Mean artery pressure } \\
(\mathrm{mmHg})\end{array}$ & 96.5 & $89.6^{\dagger}$ & $88.5^{\dagger}$ & $88.7^{\dagger}$ & $88.4^{\dagger}$ & 99 & $89.1^{\dagger}$ & $89.4^{\dagger}$ & $89.7^{\dagger}$ & $0.40,0.73,0.65,0.63$ \\
\hline $\begin{array}{l}\text { \% of patients with } \\
\text { IGT or DM }\end{array}$ & $3 \%$ & $3 \%$ & $2 \%$ & $2 \%$ & $2 \%$ & $4 \%$ & $4 \%$ & $4 \%$ & $4 \%$ & $0.53,0.36,0.36,0.36$ \\
\hline$\%$ of patients with HBP & $3 \%$ & $3 \%$ & $3 \%$ & $3 \%$ & $3 \%$ & $5 \%$ & $5 \%$ & $5 \%$ & $5 \%$ & $0.38,0.38,0.38,0.38$ \\
\hline
\end{tabular}

*Significance of difference between groups [Diag / Diag, PO3 / PO3, PO6 / PO6, LI / LI, ]. ${ }^{\dagger} p<0.05$ versus diagnosis.

arthralgias, headache, debility, sleep apnea, soft tissue swelling, and lumbodorsal pain were graded as none, slight, midrange, or severe, and were assigned as $0,1,2$, or 3 respectively. Scores of the experimental group before and after pretreatment were $(1.2 \pm 0.7) /$ $(0.5 \pm 0.5)[P=0.0028],(1.2 \pm 0.6) /(0.4 \pm 0.5)[P=0.0001]$, $(1.5 \pm 0.8) /(0.6 \pm 0.5)[P=0.0004],(1.2 \pm 0.7) /(0.4 \pm 0.6)$ [P=0.0007], $(1.0 \pm 0.7) /(0.5 \pm 0.5)[P=0.016],(1.1 \pm 0.6)$ $/(0.6 \pm 0.7)[P=0.049],(1.2 \pm 0.7) /(0.3 \pm 0.5)[P=0.0001]$, $(1.3 \pm 0.8) /(0.5 \pm 0.6)[P=0.0031],(1.1 \pm 0.5) /(0.3 \pm 0.5)$ $[P=0.0001]$. Cardiac ejection fraction was $56.8 \pm 3.7 \%$ and $62.1 \pm 3.4 \%$ before and after pretreatment $(P=0.0060)$. These results indicated that medical pretreatment relieved the typical symptoms of acromegaly. As indicated in Table 4, both the glucose tolerance and high blood pressure were significantly improved after octreotide treatment in the experimental group, which contributed to reduce the risk of surgery. Meanwhile, these improvements also could be seen in both experimental group and control group after surgery. While compared with the control group, the experimental group did not show any significant advantage either in the level of blood glucose or blood pressure, and the number of patients with IGT (impaired glucose tolerance) or DM (diabetes mellitus) or HBP (high blood pressure), during the follow-up period (respectively, at 3 and 6 months after surgery, and at the last investigation). There may have been some reasons for this discrepancy such as:1) cohort size of this study was too small to reach statistical significance; 2) DM and HBP are complex diseases and may be caused by other factors besides acromegaly. 

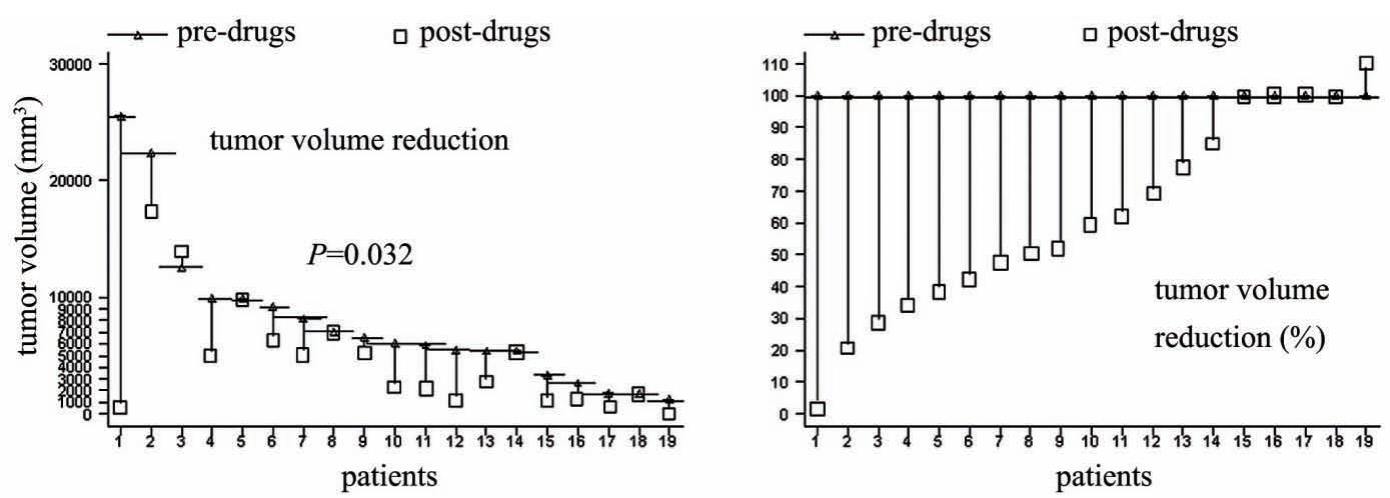

Fig. 2 Presurgical octreotide treatment reduced tumor volumes.

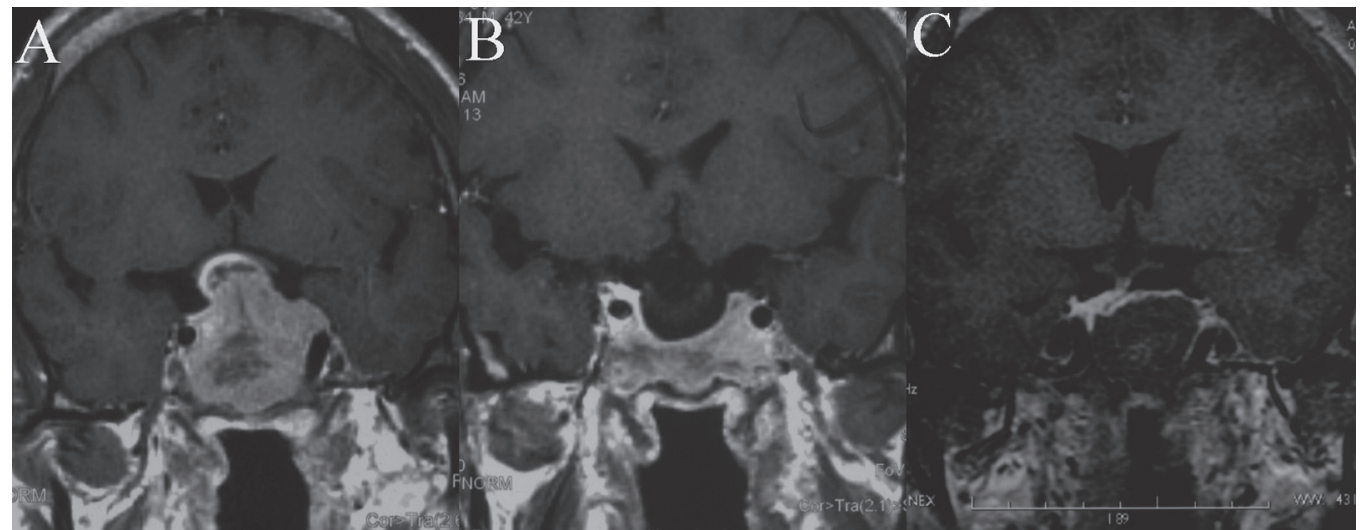

Fig. 3 Enhanced head MRI of a patient with a Hardy-Knosp Grade 3 adenoma before (A), after (B) octreotide treatment, and after surgery (C).

\section{Side-effects of drug pretreatment}

All patients in the experimental group underwent routine examination including blood chemistry, liver and renal function, serum electrolyte, electrocardiogram, and abdominal ultrasound. No obvious dysfunctions were detected. There were no significant changes of transsphenoidal surgery complications such as diabetes insipidus, CSF leakage, visual deterioration, hypothyroidism, electrolyte disturbance, liver dysfunction or cardiovascular complications between the two groups, except that the incidence of CSF leak was lower in the experimental group ( $2 / 19$ vs 9/20, $P=0.031)$.

\section{Tumor size reduction after drug pretreatment (Figs. 2, 3)}

Baseline tumor size was not different in the experimental and control groups, $7893 \pm 6450$ and $7616 \pm 6163$ $\mathrm{mm}^{3}(P=0.79)$. After pretreatment tumor size of the experimental group was significantly lower, $4794 \pm 4682$ $\mathrm{mm}^{3}(P=0.032)$. The number of patients exhibiting
$>75 \%, 50 \% \sim 75 \%, 25 \% \sim 50 \%$, or $0 \sim 25 \%$ tumor size reduction was $2,5,5$, and 7 , respectively. The mean reduction was $37.4 \pm 30.9 \%$.

\section{Comparison of tumor texture, invasion and resection rate during surgery}

Tumor texture was classified as soft, soft-firm, firm, firm-hard, or hard, and calculated as 0,1 to 4 , respectively. The degree of tumor invasion to surrounding structures was classified as none, local, extensive, and calculated as 0,1 to 2, respectively. All evaluations were performed by one experienced surgeon. Score of tumor texture and invasion degree was $1.5 \pm 1.0$ and $0.94 \pm 0.64$ in the experimental group, while the parameter for the control group was $0.8 \pm 0.5$ and $1.5 \pm 0.6$. Differences between the two groups were significant $(P=0.037$ and 0.0084) (Fig. 4). These data indicated the tumor texture was harder (Fig. 5) but the invasion was less extensive in the experimental group. Total resection rate 

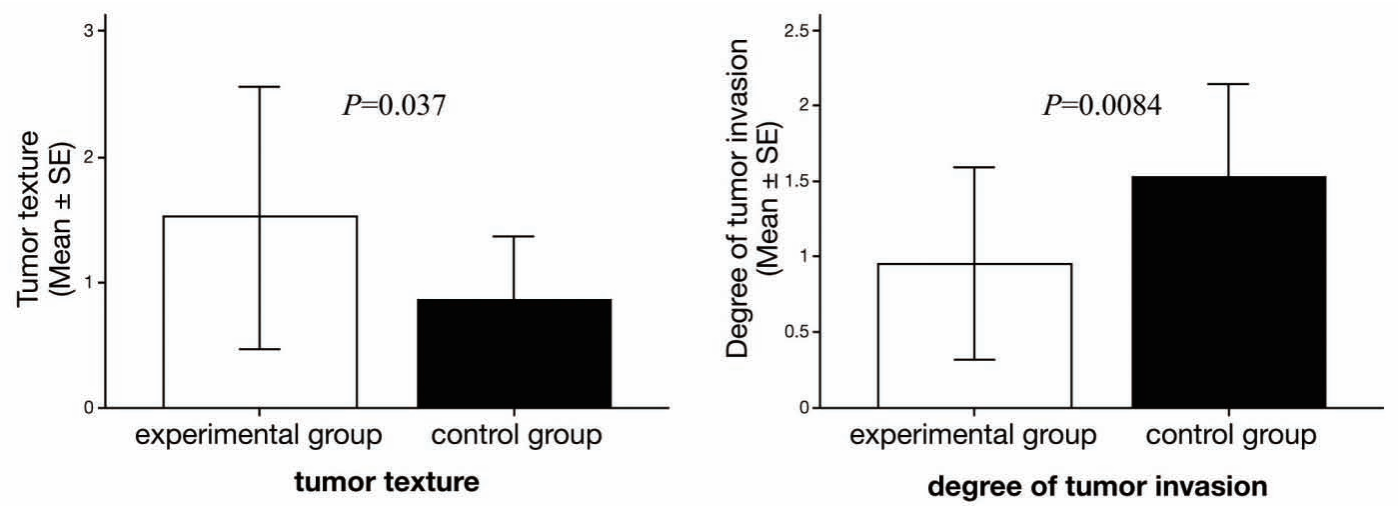

Fig. 4 Differences of tumor texture and degrees of tumor invasion to surrounding structures were significant between groups. (Tumor texture was classified as soft, soft-firm, firm, firm-hard, hard, and calculated as 0,1 to 4 respectively, in the left column. The degree of tumor invasion to surrounding structures was classified as none, local, extensive, and calculated as 0, 1 to 2 respectively, in the right column. Open column and closed column stand for the experimental and control group, respectively).

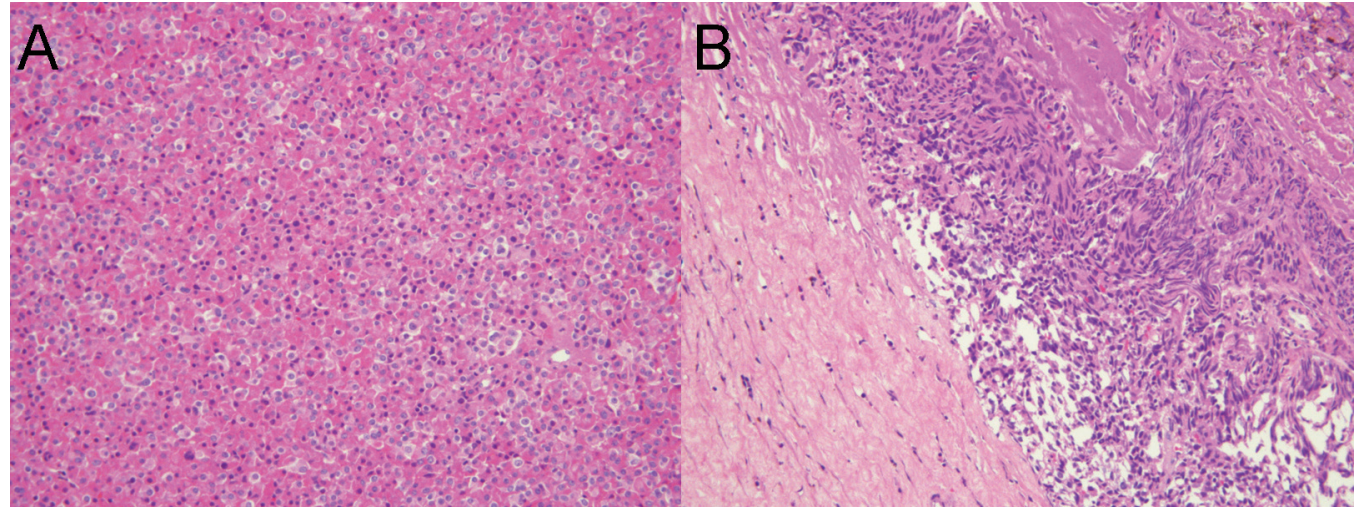

Fig. 5 Representative histological pictures of adenomas from the control (A) and experimental (B) groups. The left picture showed the tumor was rich in cells, while the right picture showed the tumor had more intra-tumoral fibrosis and cells arrangement inside it seemed more compacted.

of Hardy-Knosp Grade 2 (post-drugs) adenoma was $88.9 \%$ in the experimental group. No such adenoma was included in the control group. The total resection rates of Hardy-Knosp Grade 3 adenoma were $25 \%$ and $20 \%$ in the experimental (post-drugs) and the control groups, respectively. Total resection rates of HardyKnosp Grade 4 adenoma were 0 and 25\% in the experimental and the control groups, respectively. (Only one patient in control group got a total resection. Although she had a stage IV adenoma diffusely destroying the sellar floor, the tumor did not invade into the cavernous sinus and was totally removed with the help of neuronavigation.) Total resection rates of Hardy-Knosp Grade 5 adenoma were 0 in both groups. These data showed that there was no significant difference between the experimental and the control group on the total resection rate based on the Hardy-Knosp grading. In fact, it was almost impossible to totally resect a tumor of Hardy-Knosp grade 4 and 5. Within the experimental group, we further divided the 19 patients into two subgroups; one was those whose Hardy-Knosp grading decreased to $\leq 2(n=9)$ after drug treatment, and the other was those whose Hardy-Knosp grading is still $\geq$ $3(n=10)$ after drug treatment. There were 8 patients in the first group, but only one patient in the second group got a total resection via surgery as assessed by early postoperative MRI $(P=0.001)$ (Table 5). This result suggested that the main reason for the high total resection rates in the experimental group was the drug pretreatment made some of the tumors less invasive. 
Table 5 Detailed distribution of the invasiveness of adenomas in the experimental and control group, as well as before and after treatment in the experimental group.

\begin{tabular}{|c|c|c|c|c|c|c|c|}
\hline \multirow{2}{*}{$\begin{array}{l}\text { Hardy-Knosp } \\
\text { grading }\end{array}$} & \multicolumn{6}{|c|}{ Experimental group $\mathrm{TR} / \mathrm{n}(\%)^{* *}$} & \multirow{2}{*}{$\begin{array}{l}\text { Control group } \\
\text { TR/n (\%) }\end{array}$} \\
\hline & Pre-drugs & $\leq 2$ & 3 & 4 & 5 & Post-drugs & \\
\hline$\leq 2$ & 0 & & & & & 8/9 (88.9) & 0 \\
\hline 3 & $6 / 8(75)$ & 6/7 (85.7) & Still $30 / 1(0)$ & & & $1 / 4(25)$ & 2/10 (20) \\
\hline 4 & 2/6 (33.3) & $1 / 1(100)$ & 1/3 (33.3) & Still $40 / 2(0)$ & & $0 / 3(0)$ & $1 / 4(25)$ \\
\hline 5 & $1 / 5(20)$ & $1 / 1(100)$ & none & $0 / 1(0)$ & Still 5 0/3 (0) & $0 / 3(0)$ & $0 / 6(0)$ \\
\hline \multirow[t]{3}{*}{ Average grading } & & & $3.8 \pm 0.8$ & & & $3 \pm 1.2$ & $3.8 \pm 0.9$ \\
\hline & \multicolumn{6}{|c|}{ Subgroups in experimental group } & \\
\hline & \multicolumn{3}{|c|}{$\begin{array}{c}\text { Subgroup } 1 \\
\text { (Hardy-Knosp grading } \leq 2)\end{array}$} & \multicolumn{3}{|c|}{$\begin{array}{c}\text { Subgroup 2 } \\
\text { (Hardy-Knosp grading } \geq 3 \text { ) }\end{array}$} & $P$ value \\
\hline $\begin{array}{l}\text { Average grading } \\
\text { (pre-drugs) }\end{array}$ & \multicolumn{3}{|c|}{$3.3 \pm 0.7$} & \multicolumn{3}{|c|}{$4.3 \pm 0.7$} & 0.0089 \\
\hline Total resection rate & \multicolumn{3}{|c|}{ 8/9 (88.9) } & \multicolumn{3}{|c|}{ 1/10 (10) } & 0.001 \\
\hline
\end{tabular}

* We assigned the Hardy-Knosp grading $\leq 2$ when the tumors were $\leq$ II in grade and 0 to $\mathrm{B}$ in stage; 3 when the tumors were $\leq$ III in grade with 0 to $\mathrm{C}$ in stage, or I to II in grade with $\mathrm{C}$ in stage; 4 when the tumors were $\leq$ IV in grade with 0 to $\mathrm{D}$ in stage, or I to III in grade with D in stage; and 5 when the tumors were $\leq \mathrm{V}$ in grade or $\mathrm{E}$ in stage.

** TR stands for the number of patients achieved a total resection; n stands for the total number of patients in each subgroup; \% is the percentage.

As indicated in Table 5, the two subgroups $(\leq 2$ and $\geq 3$ ) did not show a similar distribution in HardyKnosp grading ( $3.3 \pm 0.7$ vs $4.3 \pm 0.7, P=0.0089$ ) before the octreotide treatment, and the subgroup in which the Hardy-Knosp Grading declined from 3 to 2 got the most merits from the presurgical treatment. This indicated that subgroup $\leq 2$ showed a less invasive degree than subgroup $\geq 3$, and was relatively easier to change from a less invasive adenoma to a non-invasive one after using drugs. As a result, a higher rate of total resection of the adenomas (88.9\%) was achieved in this group ( $P=0.001)$ (Fig. 3 ), which may lead to a lower recurrence in follow-up. This suggested that the status of pre-drug invasiveness was a crucial factor for the consequent surgical treatment outcome.

\section{Discussion}

According to the extensive surgical experience in our center [3], all microadenomas, and some macroadenomas with distinct capsules and no significant invasion can be readily removed via transsphenoidal surgery. On the other hand, low resection rates of the invasive macroadenomas are reported [5, 24]. As indicated by several reports, presurgical long-acting octreotide decreases tumor volume [15, 16, 25-29], and so presurgical long-acting octreotide should have greater therapeutic value, if the drug relieves the macroade- noma invasiveness [24].

In our study, the use of presurgical long-acting octreotide helped to increase the total resection rates and short-term remission rates (both GH and IGF-1 normalized) of the experimental group. We suppose the main reason was the drug pretreatment decreased tumor invasiveness and made it easier to be removed by surgery, as indicated by Fig. 4 and Table 5. However, during long-term follow-up, remission rates of the experimental group showed no advantage, likely due to the facts that all the cases in our study were patients with invasive macroadenomas. Some residual adenomas, especially when presurgical long-acting octreotide failed to reduce tumor invasiveness (Hardy-Knosp grading still $\geq 3$ ), recurred after 6 months follow-up, with reelevated nadir GH and IGF-1 levels. This suggests that patients in the above situation should be observed closely, and receive early pharmacotherapy or radiotherapy to control adenoma recurrence.

Although transsphenoidal surgery is commonly considered a procedure with low risk, most acromegaly patients have several major complications, including cardio- and cerebrovascular disease, respiratory dysfunction, hyperglycemia, and swelling of soft tissue, leading to intubation difficulty and other anesthetic risks [30]. All the patients in this series were first diagnosed, and had a long acromegaly history, without adequate treatment. In our study, presurgical long-acting 
octreotide ameliorated clinical symptoms, including carpal tunnel syndrome, acroparesthesia, hyperhidrosis, arthralgias, headache, debility, sleep apnea, soft tissue swelling, lumbodorsal pain, and also reduced glucose level and blood pressure level. This would be helpful for intubation and anesthesia, and reduce complication rates, especially for acromegaly patients with cardiac insufficiency.

Recently, owing to the application of neuronavigation, neuroendoscope, and intraoperative MRI in transsphenoidal surgery, surgical resection of pituitary adenomas has improved greatly. Patients in this series were recruited during a period of 18 months, and underwent the same surgical procedure performed by the same senior surgeon, thus decreasing the variability of the procedure due to new technology or different surgeons. Therefore, our randomized and prospective study can minimize this potential bias.

However, the total case number of our study is less than others and the follow-up time is shorter. Therefore, a controlled multicenter long term study would help resolve this important management question for acromegaly.

\section{Conclusions}

Presurgical long-acting octreotide treatment effectively reduced tumor volume and invasion, and decreased postoperative GH and IGF-1 levels, enabling improved early remission rates of transsphenoidal surgery, but did not boost the long-term curative rate. When presurgical long-acting octreotide fails to reduce tumor invasiveness, patients should be evaluated 6 months postoperatively for reoperation, pharmacotherapy or radiotherapy.

\section{Acknowledgements}

We wish to thank Dr. Shlomo Melmed, M.D. at Cedars-Sinai Medical Center, David Geffen School of Medicine, University of California, Los Angeles for his comments and advice on this manuscript.

\section{References}

1. Melmed S (2006) Medical progress: Acromegaly. $N$ Engl J Med 355: 2558-2573.

2. Nomikos P, Buchfelder M, Fahlbusch R (2005) The outcome of surgery in 668 patients with acromegaly using current criteria of biochemical 'cure'. Eur $J$ Endocrinol 152: 379-387.

3. Shou XF, Li SQ, Wang YF, Zhao Y, Jia PF, Zhou LF (2005) Treatment of pituitary adenomas with a transsphenoidal approach. Neurosurgery 56: 249-256.

4. Beauregard C, Truong U, Hardy J, Serri O (2003) Long-term outcome and mortality after transsphenoidal adenomectomy for acromegaly. Clin Endocrinol (Oxf) 58: 86-91.

5. Kreutzer J, Vance ML, Lopes MB, Laws ER Jr (2001) Surgical management of GH-secreting pituitary adenomas: an outcome study using modern remission criteria. J Clin Endocrinol Metab 86: 4072-4077.

6. Colao A, Pivonello R, Auriemma RS, Galdiero M, Savastano S, Grasso LF, Lombardi G (2008) Growth hormone-secreting tumor shrinkage after 3 months of octreotide-LAR therapy predicts the response at 12 months. J Clin Endocrinol Metab 93:3436-3442.

7. Vallette S, Serri O (2008) Octreotide LAR for the treatment of acromegaly. Expert Opin Drug Metab Toxicol 4: 783-793.

8. Colao A, Pivonello R, Auriemma RS, Galdiero M, Savastano S, Lombardi G (2007) Beneficial effect of dose escalation of octreotide-LAR as first-line therapy in patients with acromegaly. Eur $J$ Endocrinol 157: 579-587.

9. Mercado M, Borges $\mathrm{F}$, Bouterfa $\mathrm{H}$, Chang TC, Chervin A, Farrall AJ, Patocs A, Petersenn S, Podoba J, Safari M, Wardlaw J (2007) A prospective, multicentre study to investigate the efficacy, safety and tolerability of octreotide LAR (long-acting repeatable octreotide) in the primary therapy of patients with acromegaly. Clin Endocrinol (Oxf) 66: 859-868.

10. Turner HE, Thornton-Jones VA, Wass JA (2004) Systematic dose-extension of octreotide LAR: the importance of individual tailoring of treatment in patients with acromegaly. Clin Endocrinol (Oxf) 61: 224-231.

11. Bolanowski M, Bar-Andziak E, Kos-Kudla B, Krzyzanowska-Swiniarska B, Lewinski A, LomnaBogdanov E, Milewicz A, Sowinski J, Zgliczynski W (2008) Consensus statement of the Polish Society for Endocrinology: presurgical somatostatin analogs therapy in acromegaly. Neuro Endocrinol Lett 29: 59-62.

12. Yin J, Su CB, Xu ZQ, Yang Y, Ma WB, Tao W, Yang Z, Xia XW (2005) Effect of preoperative use of longacting octreotide on growth hormone secreting pituitary adenoma and transsphenoidal surgery. Chin Med Sci J 20: 23-26. 
13. Plockinger U, Quabbe HJ (2005) Presurgical octreotide treatment in acromegaly: no improvement of final growth hormone $(\mathrm{GH})$ concentration and pituitary function. A long-term case-control study. Acta Neurochir (Wien) 147: 485-493.

14. Sadoul JL (1999) Somatotrope pituitary adenomas. Contribution of presurgical treatment with somatostatin analogs. Ann Endocrinol (Paris) 60: 490493.

15. Colao A, Ferone D, Cappabianca P, del Basso De Caro ML, Marzullo P, Monticelli A, Alfieri A, Merola B, Cali A, de Divitiis E, Lombardi G (1997) Effect of octreotide pretreatment on surgical outcome in acromegaly. J Clin Endocrinol Metab 82: 3308-3314.

16. Ayuk J, Stewart SE, Stewart PM, Sheppard MC (2004) Efficacy of Sandostatin LAR (long-acting somatostatin analogue) is similar in patients with untreated acromegaly and in those previously treated with surgery and/or radiotherapy. Clin Endocrinol (Oxf) 60: 375-381.

17. Colao A, Pivonello R, Marzullo P, Auriemma RS, De Martino MC, Ferone D, Lombardi G (2005) Severe systemic complications of acromegaly. J Endocrinol Invest 28: 65-77.

18. Wilson CB (1984) A decade of pituitary microsurgery. The Herbert Olivecrona lecture. J Neurosurg 61: 814-833.

19. Melmed S, Casanueva FF, Cavagnini F, Chanson P, Frohman L, Grossman A, Ho K, Kleinberg D, Lamberts S, Laws E, Lombardi G, Vance ML, Werder KV, Wass J, Giustina A (2002) Guidelines for acromegaly management. J Clin Endocrinol Metab 87: 4054-4058.

20. (2004) AACE Medical Guidelines for Clinical Practice for the diagnosis and treatment of acromegaly. Endocr Pract 10: 213-225.

21. Melmed S, Colao A, Barkan A, Molitch M, Grossman $\mathrm{AB}$, Kleinberg D, Clemmons D, Chanson P, Laws E, Schlechte J, Vance ML, Ho K, Giustina A (2009) Guidelines for acromegaly management: an update. $J$ Clin Endocrinol Metab 94: 1509-1517.

22. Cozzi R, Attanasio R, Montini M, Pagani G, Lasio G, Lodrini S, Barausse M, Albizzi M, Dallabonzana
D, Pedroncelli AM (2003) Four-year treatment with octreotide-long-acting repeatable in 110 acromegalic patients: predictive value of short-term results? $J$ Clin Endocrinol Metab 88:3090-3098.

23. Melmed S, Jackson I, Kleinberg D, Klibanski A (1998) Current treatment guidelines for acromegaly. J Clin Endocrinol Metab 83: 2646-2652.

24. Carlsen SM, Lund-Johansen M, SchreinerT,Aanderud S, Johannesen O, Svartberg J, Cooper JG, Hald JK, Fougner SL, Bollerslev J (2008) Preoperative octreotide treatment in newly diagnosed acromegalic patients with macroadenomas increases cure shortterm postoperative rates: a prospective, randomized trial. J Clin Endocrinol Metab 93: 2984-2990.

25. Oshino S, Saitoh Y, Kasayama S, Arita N, Ohnishi T, Kohara H, Izumoto S, Yoshimine T (2006) Short-term preoperative octreotide treatment of GH-secreting pituitary adenoma: predictors of tumor shrinkage. Endocr J 53: 125-132.

26. Losa M, Mortini P, Urbaz L, Ribotto P, Castrignano T, Giovanelli M (2006) Presurgical treatment with somatostatin analogs in patients with acromegaly: effects on the remission and complication rates. $J$ Neurosurg 104: 899-906.

27. Kristof RA, Stoffel-Wagner B, Klingmuller D, Schramm J (1999) Does octreotide treatment improve the surgical results of macro-adenomas in acromegaly? A randomized study. Acta Neurochir (Wien) 141: 399-405.

28. Lucas-Morante T, Garcia-Uria J, Estrada J, Saucedo G, Cabello A, Alcaniz J, Barcelo B (1994) Treatment of invasive growth hormone pituitary adenomas with long-acting somatostatin analog SMS 201-995 before transsphenoidal surgery. J Neurosurg 81: 10-14.

29. Tauber JP, Babin T, Tauber MT, Vigoni F, Bonafe A, Ducasse M, Harris AG, Bayard F (1989) Long term effects of continuous subcutaneous infusion of the somatostatin analog octreotide in the treatment of acromegaly. J Clin Endocrinol Metab 68: 917-924.

30. Schmitt H, Buchfelder M, Radespiel-Troger M, Fahlbusch R (2000) Difficult intubation in acromegalic patients: incidence and predictability. Anesthesiology 93: 110-114. 